\title{
Análise Facial na Terapêutica Ortodôntica - uma revisão de literatura
}

\section{Facial Analysis in Orthodontic Therapy - a literature review}

\section{RESUMO}

A análise facial tem sido um recurso diagnóstico valorizado desde os primórdios da Ortodontia. Avaliar o padrão de equilíbrio estético é fundamental para nortear as condutas clínicas do ortodontista, tanto em norma frontal como o perfil facial. A criação de metas terapêuticas, para facilitar a nossa visualização, oferece parâmetros para o desenvolvimento do tratamento ortodôntico, tornando-os recursos de grande valia para o diagnóstico e prognóstico dos casos. O trabalho tem como objetivo proporcionar ao ortodontista uma visão integrada do diagnóstico estético facial, apresentando metas terapêuticas que podem contribuir para o equilíbrio e harmonia facial, bem como na contribuição para melhores resultados do tratamento ortodôntico. Palavras-chave: Análise Facial, Diagnóstico Ortodôntico.

\section{ABSTRACT}

The facial analysis has been an important diagnostic method since the beginning of Orthodontics. Evaluate the pattern of aesthetic balance is essential to guide the clinical orthodontist in both the frontal and profile facial. The creation of therapeutic goals, to facilitate our view, provides guidelines for the development of orthodontic treatment, making them invaluable resources for the diagnosis and prognosis of cases. The work aims to provide the orthodontist an integrated diagnostic facial aesthetic, featuring therapeutic targets that may contribute to facial balance and harmony, as well as contributing to better results of orthodontic treatment.

Key-words: Facial Analysis, Orthodontic Diagnostic.

\section{INTRODUÇÃO}

A análise morfológica da face é o principal recurso diagnóstico para determinação do Padrão Facial que, por sua vez, remete a protocolos de tratamento e prognósticos específicos em diferentes faixas etárias ${ }^{4}$. Cada vez mais a busca de uma face harmoniosa e de um sorriso bonito, leva pessoas a procurarem o ortodontista que possa contribuir por meio de vários tipos de tratamento ${ }^{8}$.

Segundo Teles e Vasconcelos $(2009)^{10}$, na atualidade, as análises faciais tegumentares têm sido objeto de estudos, não somente no diagnóstico e planejamento do tratamento de casos ortodôntico-cirúrgicos, mas também de casos associados à Ortopedia Funcional. Em (2011) ${ }^{18}$, considerou em estudo de revisão literária, a definição de beleza facial como o estado de harmonia e equilíbrio das proporções faciais, estabelecidas pelas estruturas esqueléticas, dentais e de tecido tegumentar, cabendo ao ortodontista conservá-las ou melhorá-las.
Réferson Melo ${ }^{1}$

Aline Vilas Boas ${ }^{2}$

Rafaela Barbosa ${ }^{3}$

${ }^{1}$ DDS, MsC, PhD. Professor do Curso de Odontologia da Universidade Estadual de Feira de Santana (UEFS) e Faculdade de Tecnologia e Ciências (UniFTC).

${ }^{2}$ DDS, MsC, PhD. Coordenadora e Professora do Curso de Odontologia da Faculdade de Tecnologia e Ciências (UniFTC).

${ }^{3}$ DDS. Pós graduada em Ortodontia pela UniFTC.

Autor para correspondência:

Nome do autor: Réferson Melo dos Santos

Endereço: Rua Aristides Novis, 139, Edf Portal da Praça, Feira de Santana-Bahia

Telefone: (71) 99932-8264 
Um parâmetro muito interessante foi desenvolvido ${ }^{3}$ para determinar a classificação dos indivíduos de acordo com seu padrão de crescimento, considerando a avaliação morfológica da face nas visões frontal e lateral. Dentro deste aspecto, os indivíduos podem ser classificados como Padrão I, II, III, Face longa e Face curta.

As faces têm harmonia de proporções, simetrias, convexidades e angulações cujas variáveis médias são amplamente utilizadas para identificar traços positivos e negativos de estética facial, orientando o profissional a diferenciar o "normal" aceitável do "anormal" inaceitável. Uma avaliação global do tecido mole de frente e de perfil é essencial para que se tenha um entendimento amplo das características estéticas do paciente ${ }^{1}$.

Diante do exposto, o trabalho tem como objetivo, proporcionar ao ortodontista uma visão integrada do diagnóstico estético facial, apresentando metas terapêuticas que podem contribuir para o equilíbrio e harmonia facial, bem como na contribuição para melhores resultados do tratamento ortodôntico.

\section{REVISÃO DE LITERATURA}

\section{Importância da Análise facial para o Diagnóstico Ortodôntico}

Com o avanço dos procedimentos ortocirúrgicos, a busca pelo equilíbrio da face recebeu um maior destaque, promovendo assim a incorporação da análise facial como um importante exame auxiliar ao diagnóstico ortodôntico. Isto resultou na intensificação da necessidade de se estudar as faces esteticamente equilibradas e a harmonia entre diferentes elementos faciais ${ }^{11}$.

Vedovello et al. , (2002) ${ }^{20}$ em uma revisão de literatura sobre análise facial e sua importância no diagnóstico ortodôntico, observaram que a análise do tecido mole deve ser o elemento fundamental para o diagnóstico ortodôntico, visando à melhora no Padrão Facial. Concluíram que para a avaliação personalizada da face, devem-se levar em consideração as diferenças raciais existentes, assim como as diferenças quanto ao gênero e ao grau de maturação em que o indivíduo se encontra e que a análise facial é indispensável para o diagnóstico ortodôntico, pois identifica as características positivas e negativas do perfil mole do indivíduo, sendo adequado associá-la à cefalometria convencional, assim como aos outros exames complementares existentes.

\section{Exames Solicitados}

A análise facial de tecido mole é imprescindível para um diagnóstico ortodôntico bem sucedido. Nesse sentido, diversas análises foram desenvolvidas para avaliar o perfil facial, algumas obtidas a partir de cefalometrias, exame clínico ou por avaliação de fotografias $^{14,15}$.

De acordo com Macedo et al., (2008) ${ }^{12}$ existem alguns requisitos que podem auxiliar no diagnóstico, como o exame clínico detalhado; fotografias faciais frontais em repouso e sorrindo, em perfil e em $3 / 4$ de perfil em repouso e sorrindo; tomografia volumétrica, Cone-Beam; e traçados fotométricos sobre as fotografias frontais em repouso e sorrindo e em perfil. Ele ainda ressalta que o melhor exame, ainda, é o exame clínico do paciente, começando com a avaliação das características faciais. 


\section{Padrão facial}

As más oclusões têm como um dos fatores etiológicos primários o padrão de crescimento facial, definido como um conjunto de regras que atuam no crescimento e desenvolvimento da face, preservando características específicas, determinadas geneticamente, sofrendo pouca ou nenhuma influência do meio ambiente ${ }^{13}$.

Atualmente, esta análise não se baseia apenas nos números cefalométricos, mas na análise visual direta do paciente ou de fotografias de frente e perfil, para classificar as faces em perfis I, II, III, padrão face curta e padrão face longa, com ou sem assimetrias ${ }^{14,15,6}$.

A análise facial numérica do perfil deve ser realizada em fotografias padronizadas, por meio de medidas angulares e proporcionais ${ }^{16}$. Um trabalho realizado em $(2008)^{17}$,constatou-se que, tanto na medição manual quanto na medição por computador, há uma diferença altamente significativa entre a medida na fotografia em repouso e em oclusão. Por isso, deve-se ter o cuidado de estabelecer em todas as fotos a mesma posição, para permitir a padronização e a comparação.

O conceito de que a determinante genética expressa na morfologia tegumentar da face condiciona de maneira primária todos seus componentes, incluindo dentes. Uma vez definida a morfologia facial, permite-se o diagnóstico e um efeito cascata de tendências ${ }^{6}$.

\section{PAdRão I}

O indivíduo Padrão I caracteriza-se pela normalidade nas relações esqueléticas sagitais e verticais, nas avaliações de frente e de perfil ${ }^{3}$.

Na análise morfológica frontal, os portadores de Padrão I apresentam simetria aparente, proporção entre os terços faciais volume proporcional do vermelhão dos lábios e selamento labial passivo. Qualquer má oclusão que esses indivíduos apresentem é apenas dentária, não associada a qualquer discrepância esquelética sagital ou vertical.

Na avaliação do perfil, o Padrão I é caracterizado por um grau moderado de convexidade. A expressão da maxila na face é identificada pela presença da projeção zigomática e depressão infraorbitária, que podem ser verificadas também na visão frontal.

Da analise cefalométrica, espera-se que as medidas estejam compreendidas dentre aquelas ditas como normais.

\section{Padrão II}

No grupo dos indivíduos que apresentam algum tipo de alteração óssea, os indivíduos classificados como Padrão Facial II são aqueles que apresentam um perfil demasiadamente convexo. Essa alteração pode ser causada por três combinações diferentes de desarmonia óssea: excesso maxilar, deficiência mandibular ou combinação de ambos ${ }^{18 .}$

O padrão II apresenta convexidade facial aumentada, em conseqüência do excesso maxilar, mais raro, ou pela deficiência mandibular ${ }^{2}$. A linha queixo e pescoço é muito útil para diagnosticar a localização da displasia, pois quando estiver boa, a doença está na maxila, porém se estiver curta, existe deficiência mandibular ${ }^{18}$.

Apresenta, usualmente, um ângulo nasolabial bom, associado ao sulco mentolabial marcado pela eversão do lábio inferior com excesso de exposição do vermelhão ${ }^{14,15}$.

A má oclusão mais freqüente é a classe II, que reflete a discrepância maxilo-mandibular presente. Os pacientes tratados ou naturalmente compensados podem apresentar oclusão normal. $\mathrm{O}$ arco dentário superior é geralmente atrésico ${ }^{3}$.

\section{Padrão III}

Apresentam características faciais peculiares, essencialmente perfil reto ou côncavo (menos frequente), deficiência maxilar, prognatismo mandibular ou a combinação de am- 
bos $^{3,14,15,19}$. Na análise frontal, a projeção do terço médio tende a estar deficiente, mesmo quando a maxila estiver normal, porém em menor grau de evidência. $O$ terço inferior da face tende ao aumento e a linha queixo e pescoço se estiver boa, indica deficiência maxilar, enquanto que aumentada, prognatismo mandibular. O sulco mentolabial encontra-se aberto, devido a verticalização compensatória dos incisivos inferiores ${ }^{7}$.

\section{Padrão face longa e Face Curta}

Os pacientes classificados como Padrões face longa e curta apresentam uma discrepância vertical visível nas avaliações de frente e perfil.

O Padrão face longa é caracterizado pelo excesso na altura facial, resultando em ausência de selamento labial, convexidade facial aumentada, expressão maxilar deficiente e linha queixo e pescoço curta ${ }^{3}$.

Para o indivíduo, a principal reclamação é a exposição dentária excessiva e a exposição gengival também excessiva. As características deste tipo de padrão são clara e facilmente identificadas na maioria dos casos, tais como a base nasal estreita, o nariz longo, a área zigomática plana, o terço inferior da face longo e desproporcional ao terço médio e lábio superior não é capaz de cobrir todo o incisivo superior, dando aspecto de curto, enquanto que o inferior apresenta vermelhão excessivo e sulco mentolabial forte, Capelozza ${ }^{3,5,9}$. Outro tipo de padrão comprometido verticalmente, e de forma oposta ao descrito acima, é o Padrão Face Curta. A deficiência vertical no aspecto facial é ainda mais evidente no perfil. Estes indivíduos também apresentam algumas peculiaridades, sendo a falta de exposição dentária em repouso e a pouca expressão no sorriso ${ }^{14,15}$.

$\mathrm{Na}$ análise frontal, a face apresenta-se quadrada e larga, além da altura facial diminuída. Os indivíduos podem apresentar incisivos bem posicionados em relação ao lábio, o nariz será largo ou normal, com boa presença de zigomático e selamento labial é compressivo ${ }^{3,5}$.

Já o perfil, tende a ser reto ou levemente convexo. As aparências do zigomático e do nariz são normais, a altura inferior facial está diminuída, o ângulo nasolabial é normal ou agudo e o sulco mentolabial marcado e profundo. A linha queixo e pescoço tende a estar normal ou aumentada.
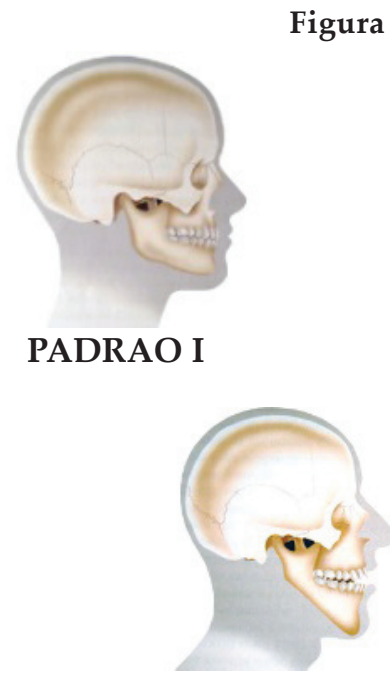

FACE LONGA

Figura 1 - Morfologia da Face

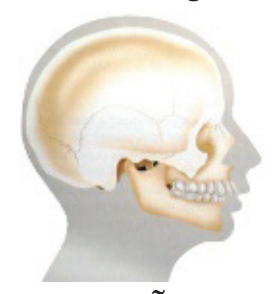

PADRÃO II

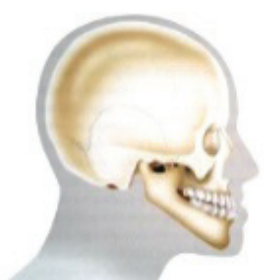

PADRÃO III

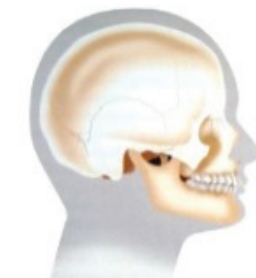

FACE CURTA 


\section{CONCLUSÕES}

O aumento da demanda por tratamentos ortodônticos deve-se à valorização da estética, especialmente a facial. A necessidade do conhecimento dos padrões estéticos faciais, assim como um diagnóstico preciso somado a metas terapêuticas individualizadas, tanto em aspectos funcionais quanto estéticos é essencial para o sucesso do tratamento ortodôntico, uma face harmoniosa.

\section{REFERÊNCIAS BIBLIOGRÁFICAS}

1. Arnett, GW, Bergman, RT. Chaves Faciais para o Diagnóstico e Plano de Tratamento Ortodôntico, Parte II. Am J Orthod Dentofac Orthop,1993;103(5):395-411.

2. Brandão AM, Vigorito JW, Filho LC. Avaliação das características do perfil tegumentar em pacientes com má oclusão Classe II divisão 1 por meio da análise facial numérica. Ortodont 2001;34(2):59-65.

3. Capelozza FL. Diagnostico em Ortodontia. 1.ed. Maringá: Dental Press; 2004.

4. Capelozza FL, Souza 1, Cavassan SLMC, Ozawa TO. A altura facial anterior inferior na Classe II divisão primeira por deficiência mandibular. Rev Dent Press Ortodon Ortop Facial 2004;9(6):39-47.

5. Cardoso CA, Bertoz F, Capelozza Filho L, Reis S. Caracteristicas cefalométricas do padrão face longa. Rev Dent Press Ortodon Ortop Facial 2005;10(2):29-43.

6. Cavichiolo JC, Salazar M, Cuogghi OA, Mendonça MR, Furguim LZ. Avaliação da agradabildade facial de pacientes portadores de padrão facial II e III por ortodontistas e leigos. Odonto 2010;36(18):73-81.

7. Colombo V, Moro A, Rech R, Verona J, Costa G. Análise facial frontal em repouso e durante o sorriso em fotografias padronizadas. Parte I: avaliação em repouso. Rev Dent Press Ortodon Ortop Facial 2004;9(3):86-97.

8. Delalíbera HVC, Da Silva, MC, Pascotto RC, Terada HH, Terada RSS. Avaliação estética de pacientes submetidos a tratamento ortodôntico. Acta Sci Health 2010;32(1):93-100.

9. Enoki C, Telles CS,Matsumoto MAN.Dental-skeletal dimensions in growing individuals with variations in the lower facial height. Braz Dent J 2004; 1(15):68-74.

10. Feres R, Vasconcelos MHF. Estudo comparativo entre a Análise Facial Subjetiva e a Análise Cefalométrica de Tecidos Moles no diagnóstico ortodôntico. Rev Dent Press Ortodon Ortop Facial 2009;14(2):81-8.

11. Gianníou E, Kolokithas G, Athanasiou AE. The use of extraoral photographs for predictíng dentoalveolar and skeletal characterístícs ín persons seekíng orthodontic treatment. Heleníc Orthod Review 2003;6(2):147-62.

12. Macedo A, Moro A, Júnior HS, Martins LF. A análise facial no diagnóstico e planejamento ortodôntico. Ortodontia SPO 2008;41(2):148-53.

13. Martins GAS, Bastos FG, Thomaz EBAF, Dias MM, Silva TSO, Silva SO, Moura CDVS, Moura WL. Padrão Facial e Indicação de Cirurgia Ortognática. Rev. cir. traumatol. buco-maxilo fac 2014;14(1):75-82.

14. Reis SAB. Estudo Comparativo do perfil facial dos padrões I, II e III portadores de selamento labial passivo. Rev Dent Press Ortodon Ortop Facial 2006; 11(4):36-45.

15. Reis SAB, Abrão J, Filho LC, Claro CAA. Análise facial numérica do perfil de brasileiros Padrão I. Rev Dent Press Ortodon Ortop Facial 2006;11(6):24-34.

16. Scanavini MA, Trevisan F, Maltagliati LA, Dos Santos JE, Martelli Filho JA. Novo dispositivo para obtenção de fotografi as frontais e laterais padronizadas. J Bras Ortodon Ortop Facial 2003;45(8):245-50.

17. Schlickmann ICA, Moro A, Dos Anjos A. Análise do perfil facial masculino adulto jovem, esteticamente agradável, em fotografias padronizadas: comparação da medição manual com a computadorizada. Rev Dental Press Ortodon Ortop Facial 2008;13(6):98-107.

18. Silva Filho OG, Silva P, Regp M, Silva F, Cavassan A. Epdemiologia da má oclusão na dentição decídua. Ortodontia 2005;1(5):22-33.

19. Silva Filho OG, Magro AC, Ozawa TO. Má oclusão de classe III: caracterização morfológica na infância (dentadura decídua e mista. Ortodontia 1997;30(2):7-18.

20. Vedovello MF. Diagnóstico Dentofacial. 1 ed. São Paulo: Napoleão; 2011.

21. Vedovello MF, Rossi ACS, Neto GI, Vedovello SAS, Valdrighi HC. Análise Facial e sua Importância no Diagnóstico Ortodôntico. J Bras Ortodon Ortop Facial 2002;7(39):218-25. 